\title{
A Ce-Nd-Hf isotopes perspective on the EMI-EMII end-members distinction
}

R. DOUCELANCE', C. ISRAEL', M. BOYET', P. BONNAND', M. G. JACKSON ${ }^{2}$, J. BARLING ${ }^{3}$

Université Clermont Auvergne, CNRS, IRD, OPGC, Laboratoire Magmas et Volcans, F-63000 ClermontFerrand, France

Department of Earth Science, University of California, Santa Barbara, CA, USA

${ }^{3}$ Department of Earth Sciences, University of Oxford, OX1 3AN, United Kingdom

Oceanic Islands Basalts (OIB) provide good means to access the mantle composition. Multi-isotopic studies of OIB have shown large variations at local (island- and/or archipelago scales) and global scales that lead to the definition of several mantle end-members, termed DMM, HIMU, EMI and EMII.

Although the existence of these end-members is now accepted, no consensus has been reached about their exact nature. For example, EM-like signatures are generally thought to be inherited from the recycling via subduction of either pelagic or terrigeneous sediments in the mantle source of OIB, while alternative models rather suggest a dominant impact of the subduction of oceanic plates or delamination of subcontinental materials.

The Lanthanum-Cerium (La-Ce) isotopic systematics relies on the radioactive decay of the long-lived 138La isotope to the radiogenic 138Ce (half-life of $292.5 \mathrm{Gyr}$ ). Cerium is well-known for its change of valence from $\mathrm{Ce} 3+$ to $\mathrm{Ce} 4+$ under oxidized conditions. Such a behavior results in Ce elemental anomalies in pelagic sediments that increase their $\mathrm{La} / \mathrm{Ce}$ ratio and consequently the long-term evolution of their Ce isotopic composition compared to that of continental-derived material.

Here we present the first $\mathrm{Ce}$ isotope analyzes together with new Sr-Nd-Pb-Hf data for samples from the Samoa archipelago (EMII-like OIB) and compare them with those of EMI-like basalts from Gough [1] and Heard Islands [2]. Results show no distinction between Samoa and Heard for which Ce-Nd-Hf isotopic compositions cover most of the mantle array. In contrast, Gough displays a similar range of $\mathrm{Ce}$ isotopic compositions but with a restricted field for $\mathrm{Nd}$ and $\mathrm{Hf}$ isotopes. Although the EMI-EMII distinction is well established in classical, $\mathrm{Sr}-\mathrm{Nd}-\mathrm{Pb}$ isotope variation diagrams, Ce ratios may provide new perspectives on the nature of the materials involved in these OIB sources.

[1] Boyet et al. (2019) G-cubed 20 ; [2] Israel et al. (2020) EPSL 530, 115941 